\title{
ANTERIOR TALOFIBULAR LIGAMENT (ATFL) RECONSRUCTION WITH MODIFIED BROSTROM-GOULD TECHNIQUE USING FIBER WIRE
}

\author{
Andre Triadi Desnantyo ${ }^{\mathbf{1}}$, Mouli Edward ${ }^{\mathbf{1}}$, Asyumaredha ${ }^{2 *}$

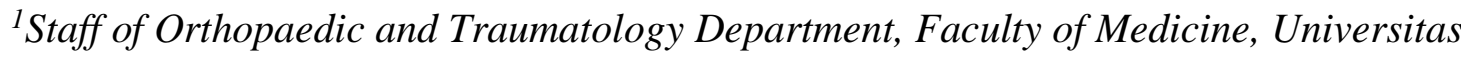 \\ Airlangga/Dr Soetomo General Hospital, Surabaya \\ ${ }^{2}$ Resident of Orthopaedic and Traumatology Department, Faculty of Medicine, Universitas \\ Airlangga/Dr Soetomo General Hospital, Surabaya \\ *Corresponding Author: Asyumaredha, Resident of Orthopaedic and Traumatology \\ Department, Faculty of Medicine, Universitas Airlangga/Dr Soetomo General Hospital, Jl. \\ Mayjen Prof. Dr. Moestopo 6-8, Surabaya. \\ E-mail: maredha.asriel@gmail.com
}

\begin{abstract}
ABSTRAK
Latar belakang: Cedera pada ligamen ankle dilaporkan 1 dari setiap 10.000 orang perhari. Dimana penderita terbanyak adalah laki-laki 22-24 tahun dan aktif berolahraga. Pada kasus ini dilaporkan 2 pasien (perempuan umur 15 tahun dan laki-laki umur 21 tahun).

Kasus: Kami melaporkan 2 kasus, laki-laki 21 tahun dan perempuan 15 tahun, sama-sama mengalami cedera ligamen anterior talofibular, keduanya memiliki skor AOFAS fair (nilai di bawah 80) serta pada pemeriksaan MRI didapatkan ruptur dari ATFL.

Diskusi: Setelah mengalami cedera saat berolahraga, kedua pasien dibawa ke rumah sakit dan dilakukan pemeriksaan fisik (dengan nilai AOFAS fair) dan radiologis, didapatkan kesimpulan bahwa mengalami robekan ligamen anterior talofibular kemudian diputuskan untuk rekonstruksi dengan menggunakan teknik modified Brostrom-Gould menggunakan fiber wire. Setelah dilakukan evaluasi \pm 3 bulan dilakukan evaluasi ulang fisk dan radiologis didapatkan nilai AOFAS yang excellent dan kedua pasien tidak mengalami gangguan dalam kegiatan harian.

Kesimpulan: ATFL merupakan ligamen bagian lateral yang berfungsi menahan gerakan ke arah plantar fleksi. Teknik modified Brostrom-Gould dengan fiber wire didapatkan hasil yang memuaskan.
\end{abstract}

Kata kunci: Brostrom-Gould, AOFAS, ATFL

\begin{abstract}
Background: The incident of ankle sprain reported 1 of 10.000 case each day. The most incident was male about 22-24 year and sport active. We reported 2 cases (15 years old female and 21 years old male) both of them played routine basketball and futsal.

Case: We reported 2 cases, male 21 years old and female 15 years old, both of them suffered from anterior talofibular ligament rupture, with AOFAS score fair (below 80 point) from the MRI there is rupture of ATFL.

Discussion: The patient administered to the hospital after injury at sport. By physical examination (fair at AOFAS score) and radiological finding, they was decided underwent rupture anterior talofibular ligament and prepared for reconstruction with modified BrostromGould technique using fiber wire. After \pm 3 month, the evaluation from physical diagnostic, radiology and we got an excellent AOFAS score, which means the 2 patient got really satisfaction and has no limitation at doing daily activities.

Conclusion: ATFL is one of the lateral ligament of the ankle which protect the foot while moving at plantar flexion. Modified Brostrom-Gould technique using fiber wire gave good result for reconstruction ATFL rupture for these 2 patients.
\end{abstract}

Keywords: Brostrom-Gould, AOFAS, ATFL 


\section{PENDAHULUAN}

Setiap hari sekitar 1 dari 10.000 orang mengalami cedera inversi pergelangan kaki. Tujuh hingga sepuluh persen dari semua kejadian yang ditemui di IGD rumah sakit disebabkan oleh ankle sprain. Sprain ligament ankle merupakan cedera yang sering terjadi, terutama banyak terjadi pada komplek ligamen lateral. Ankle sprain lebih banyak ditemukan pada individu di bawah 35 tahun, yang berarti bahwa cedera ini sebagian besar melibatkan populasi muda yang aktif. Laki-laki berusia antara 15-24 tahun dan perempuan berusia 30 tahun memiliki peluang terkena ankle sprain lebih tinggi. Setengah dari semua keseleo pergelangan kaki $(58,3 \%)$ terjadi selama kegiatan atletik, dengan basket $(41,1 \%)$, dan sepak bola (7,9\%). Hal ini dapat membuktikan bahwa persentase tertinggi ankle sprain terjadi selama berolahraga. ${ }^{3}$ Pada 2/3 kasus datang dengan derajat cedera grade 1 atau 2. Cedera ankle merupakan $25 \%$ dari cedera pada seluruh olahraga, dimana $21-53 \%$ cedera pada basket dan 17-29\% pada sepak bola.

Gejala yang biasanya terlihat adalah kekakuan pergelangan kaki yang menetap, pembengkakan dan nyeri dengan sinovitis yang tertunda, tendinitis dan kelemahan otot. Fenomena 'giving away' seringkali dapat diamati. Membuat diagnosis yang andal dan akurat tidaklah mudah, karena beberapa gejala tergantung pada subjektivitas pasien yang hadir pada saat pemeriksaan.

Struktur yang mendukung stabilitas pergelangan kaki termasuk dalam kompleks ligamen lateral yang dibentuk oleh tiga ligamen kapsular: anterior talofibular (ATFL), calcaneofibular (CFL) dan posterior talofibular (PTFL). ATFL dan CFL adalah stabilitator utama dari sisi lateral pergelangan kaki. ATFL adalah ligamen yang paling umum mengalami cedera. Kombinasi gangguan ATFL dan CFL merupakan pola cedera paling umum kedua.

Penanganan ankle sprain biasanya disesuaikan dengan tingkat keparahan. Klasifikasi ankle sprain yang paling umum digunakan dalam praktik klinis, yaitu grade I (ringan), grade II (sedang) dan grade III (berat). Grade I dan II umumnya akan pulih dengan manajemen konservatif, namun pada grade III manajemen pengobatannya masih menjadi perdebatan. Ada yang memilih bedah primer, namun ada yang memilih perawatan konservatif. Menurut Trč, Handl dan Havlas, pembedahan direkomendasikan untuk mengembalikan fungsi normal pergelangan kaki dan ligamennya, terutama pada pasien yang menderita rasa sakit dan ketidakstabilan berjalan di medan yang tidak rata berdasarkan lesi kronis ATFL. Lebih dari 50 teknik bedah telah dijelaskan untuk 


\section{Laporan Kasus}

Vol 8 No. 2, Oktober 2019

ISSN 2460-8742

http://journal.unair.ac.id/ORTHO@journal-orthopaedi-and-traumatology-surabaya-media-104.html

merekonstruksi ligamen pergelangan kaki dan memperbaiki ketidakstabilan pergelangan kaki, sebagian besar dengan tingkat keberhasilan $80-90 \%$. Salah satu teknik yang digunakan adalah teknik modifikasi Brostrom-gould.

Teknik modifikasi Brostrom-gould mulanya dikembangkan oleh Broström pada tahun 1966 dan melibatkan perbaikan langsung ligamen pergelangan kaki lateral. Gould et al kemudian memodifikasi gambaran rekonstruksi anatomi yang melibatkan mobilisasi dan pemasangan retinakulum ekstensor sebagai perbaikan. Penelitian yang dilakukan oleh Wainright $e t$ al. menunjukkan adanya perbaikan anatomi menggunakan teknik modifikasi Brostromgould dalam membantu mengembalikan gerakan normal setelah pergelangan kaki lateral yang tidak stabil. Sebuah penelitian lain yang dilakukan di populasi pasien dengan instabilitas persendiaan kaki lateral menemukan perbedaan yang signifikan pada in vivo kinematik unstables ankle dibandingankan sisi yang sehat pada persendiaan pergelangan kaki di bawah kondisi pembebanan quasi static. Teknik modifikasi Brostrom-gould menunjukkan perbaikan signifikan dalam menurunkan translasi anterior talus sekitar $1 \mathrm{~mm}$ pada $100 \%$ berat badan dan menurunkan rotasi internal talus sekitar $3^{\circ}$ pada $75 \%$ dan $100 \%$ berat badan.
Penelitian ini memaparkan studi kasus rekonstruksi talofibular ligamen (ATFL) anterior dengan teknik modifikasi Brostrom-gould dengan menggunakan fiber wire.

Tabel 1. Skor AOFAS

\begin{tabular}{|l|l|}
\hline \multicolumn{2}{|c|}{ AOFAS ANKLE-HINDFOOT SCALE (100 POINTS } \\
\hline \multicolumn{2}{|c|}{ TOTAL) } \\
\hline Pain (40 points)
\end{tabular}


Laporan Kasus

Vol 8 No. 2, Oktober 2019

ISSN 2460-8742

http://journal.unair.ac.id/ORTHO@journal-orthopaedi-and-traumatology-surabaya-media-104.html

\begin{tabular}{|l|c|} 
valgus) & \\
\hline - Stable & 8 \\
\hline - Unstable & 0 \\
\hline Alignment (10 points) & 10 \\
\hline $\begin{array}{l}\text { - Good, plantigrade foot, well-aligned forefoot } \\
\text { and hindfoot }\end{array}$ & 5 \\
\hline $\begin{array}{l}\text { - Fair, plantigrade foot, some degree of } \\
\text { misalignment of the ankle and hindfoot, } \\
\text { asymptomatic }\end{array}$ & 0 \\
\hline $\begin{array}{l}\text { •Poor, non-plantigrade foot, strong and } \\
\text { symptomaticmisalignment }\end{array}$ & \\
\hline TOTAL SCORE:_100_- & \\
\hline
\end{tabular}

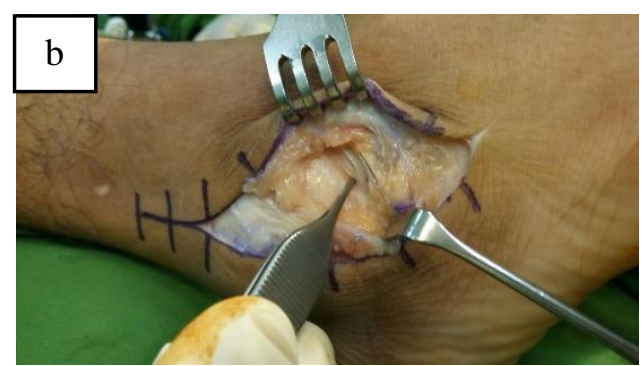

Ada 3 kategori pada penilaian AOFAS yakni: $:^{10}$

- Excellent 90-100

- $\quad$ Good 80-90

- Fair di bawah 80

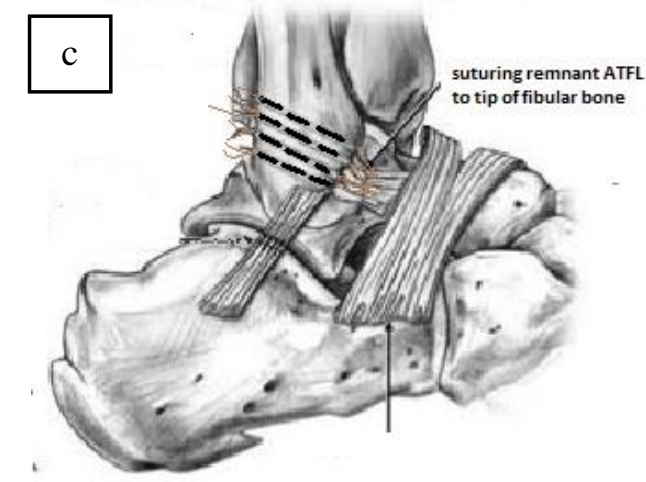

\section{Teknik Modifikasi Brostrom-Gould}

Teknik Modifikasi Brostrom-Gould (Gambar 1) merupakan metode standar untuk memperbaiki anatomis dari simptomatis kronik instabilitas ankle lateral, karena: ${ }^{11}$

1. Tekniknya jelas

2. Bisa mencapai ROM ankle secara penuh

3. Membantu memperbaiki instabilitas ligamen subtalar

4. Memperbaiki instabilitas fungsional

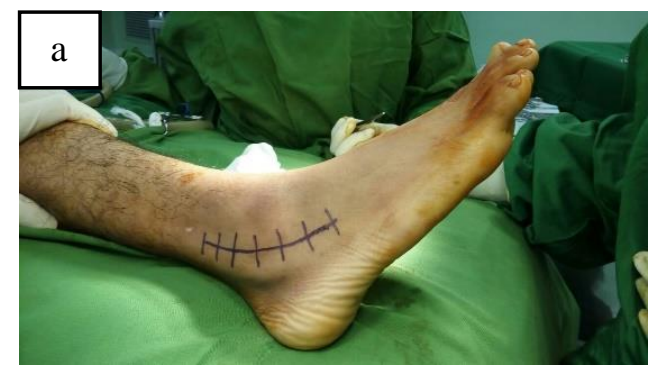

\section{LAPORAN KASUS}

\section{Kasus 1}

Laki-laki berumur 21 tahun dengan Anterior Talofibular Ligament rupture dan syndesmotic injury, dengan nyeri saat berjalan sejak 2,5 bulan yang lalu. Riwayat jatuh terpeleset saat bermain futsal dengan 


\section{Laporan Kasus}

Vol 8 No. 2, Oktober 2019

ISSN 2460-8742

http://journal.unair.ac.id/ORTHO@journal-orthopaedi-and-traumatology-surabaya-media-104.html

posisi punggung kaki tertekuk pada tanggal

27 Mei 2016. Pada pemeriksaan pada pergelangan kaki kanan didapatkan swelling, oedem, nyeri tekan, serta ROM terbatas saat melangkah. Anterior drawer test (+), Varus test (-) Valgus test (-). Skor AOFAS adalah fair (53) seperti dijabarkan pada Tabel 2. Pada MRI tampak tear dari ATFL (Gambar 2).

Tabel 2. Skor AOFAS kasus 1

\begin{tabular}{|c|c|}
\hline \multicolumn{2}{|l|}{ AOFAS ANKLE-HINDFOOT SCALE } \\
\hline \multicolumn{2}{|l|}{ Pain } \\
\hline - Moderate, daily & 20 \\
\hline $\begin{array}{l}\text { Functional (50 points) Restraints in } \\
\text { activities, support required }\end{array}$ & \\
\hline $\begin{array}{l}\text { - Restraints in daily and recreational activities, } \\
\text { cane required }\end{array}$ & 4 \\
\hline Maximum walking distance, in blocks & \\
\hline - Less than 1 & 0 \\
\hline Walking surfaces & \\
\hline $\begin{array}{l}\text { - Strong difficulties on irregular floors, stairs, } \\
\text { steeps and hills }\end{array}$ & 0 \\
\hline Gait abnormality & \\
\hline - Strong & 0 \\
\hline Sagittal mobility (flexion + extension) & \\
\hline - Normal or slightly limited (30॰ or more) & 8 \\
\hline Hindfoot mobility (inversion + eversion) & \\
\hline - Moderate limitation ( $25-74 \%$ of the normal) & 3 \\
\hline $\begin{array}{l}\text { Ankle-Hindfoot stability (anteroposterior, } \\
\text { varus-valgus) }\end{array}$ & \\
\hline - Stable & 8 \\
\hline Alignment (10 points) & \\
\hline $\begin{array}{l}\text { - Good, plantigrade foot, well-aligned forefoot } \\
\text { and hindfoot }\end{array}$ & 10 \\
\hline TOTAL SCORE:_53 & \\
\hline
\end{tabular}

Pemeriksaan penunjang

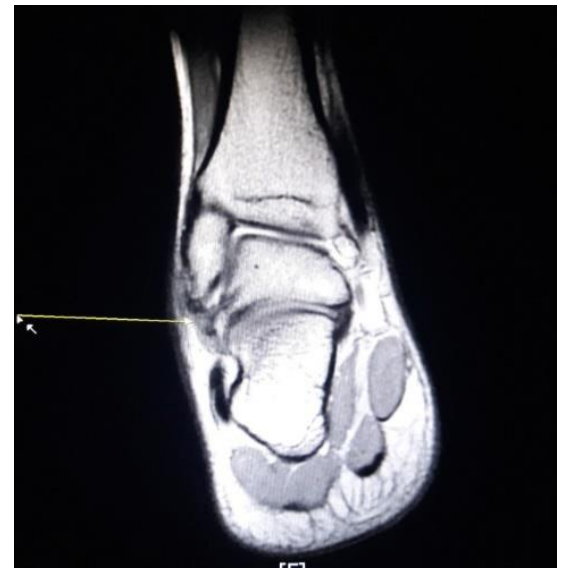

Gambar 2. MRI ankle

Pada gambar 2 tampak tear dari ATFL.

\section{Diagnosis kerja}

Ruptur Anterior Talofibular ligament Ankle

Dextra + Ruptur Deltoid Ligamen

\section{Penatalaksanaan}

Dilakukan rekonstruksi anterior talofibular ligamen dengan menggunakan teknik Brostrom-Gould modifikasi.

\section{Follow up}

Evaluasi setelah 2 bulan pasien sudah bisa melakukan aktivitas sehari-hari. Didapatkan skor excellent (100) seperti pada Tabel 3 berikut.

Tabel 3. Skor AOFAS post rekonstruksi

\begin{tabular}{|l|c|}
\hline \multicolumn{2}{|c|}{ AOFAS ANKLE-HINDFOOT SCALE } \\
\hline Pain & 40 \\
\hline • No pain & \\
\hline $\begin{array}{l}\text { Functional (50 points) Restraints in } \\
\text { activities, support required }\end{array}$ & 10 \\
\hline • No restraints, no support & 5 \\
\hline Maximum walking distance, in blocks & \\
\hline - More than 6 & \\
\hline Walking surfaces & \\
\hline
\end{tabular}


Laporan Kasus

Vol 8 No. 2, Oktober 2019

ISSN $2460-8742$

http://journal.unair.ac.id/ORTHO@journal-orthopaedi-and-traumatology-surabaya-media-104.html

\begin{tabular}{|l|c|}
$\begin{array}{l}\text { • Some difficulty on irregular floors, stairs, } \\
\text { steeps and hills }\end{array}$ & 3 \\
\hline Gait abnormality & 8 \\
\hline$\cdot$ No abnormality, mild & \\
\hline Sagittal mobility (flexion + extension) & 8 \\
\hline • Normal or slightly limited (30 or more) & 6 \\
\hline Hindfoot mobility (inversion + eversion) & \\
\hline $\begin{array}{l}\text { normal or slightly limited (75- 100\% of the } \\
\text { normal mobility) }\end{array}$ & 6 \\
\hline $\begin{array}{l}\text { Ankle-Hindfoot stability (anteroposterior, } \\
\text { varus-valgus) }\end{array}$ & 8 \\
\hline • Stable & 10 \\
\hline Alignment (10 points) & \\
\hline $\begin{array}{l}\text { - Good, plantigrade foot, well-aligned forefoot } \\
\text { and hindfoot }\end{array}$ & 10 \\
\hline TOTAL SCORE:_100_ & \\
\hline
\end{tabular}

\section{Pemeriksaan Radiologi}

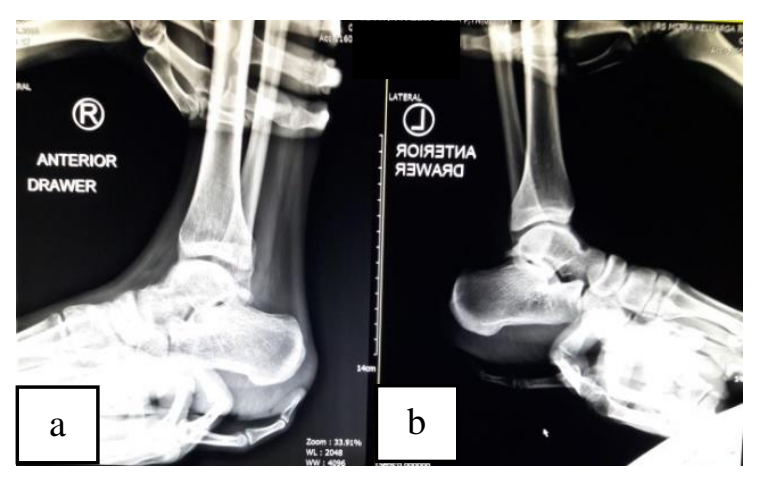

Gambar 4. Anterior drawer test

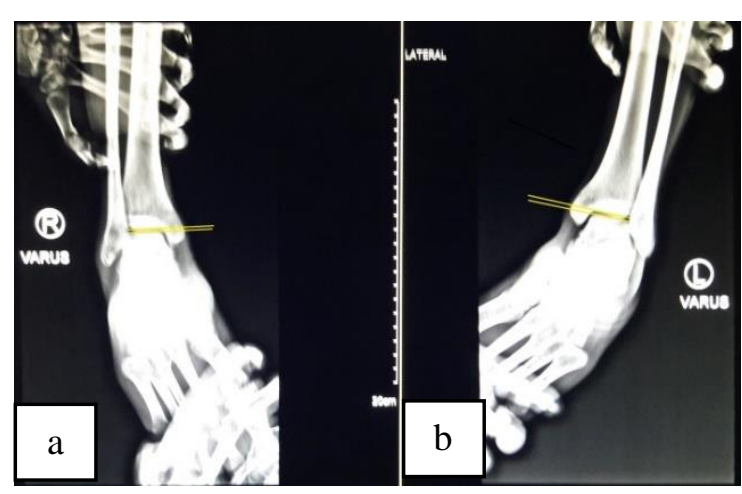

Gambar 5. Varus stress test. (a) kanan dan (b) kiri

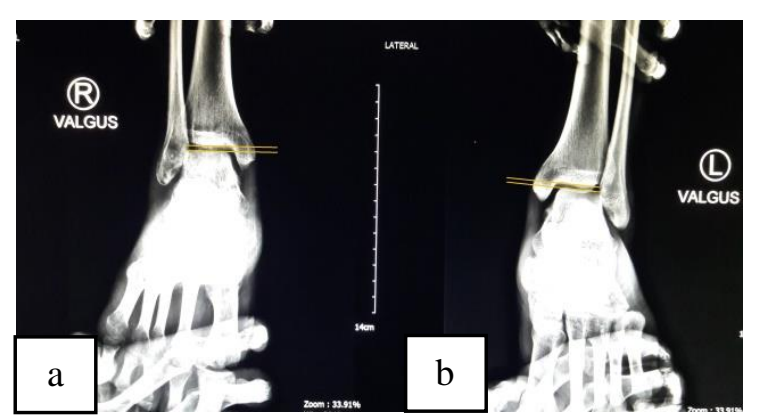

perbedaan posisi pergelangan kaki saat berdiri. Pada pemeriksaaan didapatkan anterior drawer test positif (Gambar 4), varus stress test negatif (Gambar 5), dan valgus strees test negatif (Gambar 6).

Gambar 3. Dua bulan pasca rekonstruksi.

(a) sisi anterior, (b) sisi posterior

Pada Gambar 3 tidak terdapat

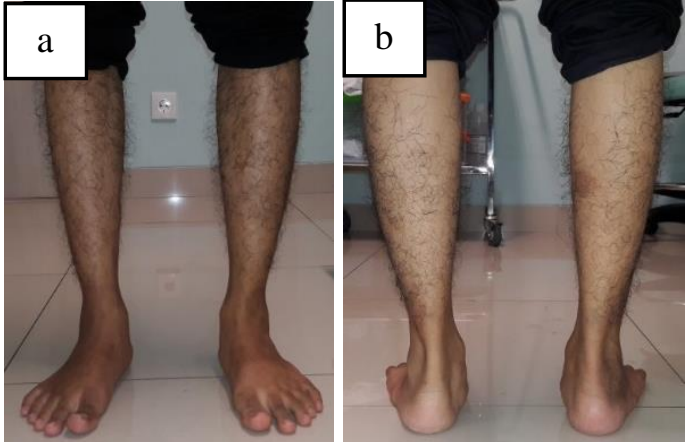

Gambar 6. Valgus stress test. (a) kanan dan (b) kiri

$>$ Kasus 2

Perempuan umur 15 tahun dengan Anterior Talofibular Ligament ruptur, dengan nyeri saat melangkah pada kaki kiri 


\section{Laporan Kasus}

Vol 8 No. 2, Oktober 2019

ISSN $2460-8742$

http://journal.unair.ac.id/ORTHO@journal-orthopaedi-and-traumatology-surabaya-media-104.html

sejak 1 bulan yang lalu. Riwayat jatuh dengan posisi punggung kaki kiri menyentuh lantai saat bermain basket pada 1 Februari 2016. Pada pemeriksaan ankle Sinistra didapatkan swelling, oedem, nyeri tekan serta ROM terbatas saat melangkah. Anterior drawer test (+), varus test (-), valgus test (-). Skor AOFAS fair (76) seperti dijabarkan pada Tabel 4. Pemeriksaan MRI (Gambar 7a dan 7b) tampak tear dari ATFL

Tabel 4. Skor AOFAS kasus 2

\begin{tabular}{|c|c|}
\hline \multicolumn{2}{|l|}{ AOFAS ANKLE-HINDFOOT SCALE } \\
\hline Pain & \\
\hline - No pain & 40 \\
\hline $\begin{array}{l}\text { Functional ( } 50 \text { points) Restraints in activities, } \\
\text { support required }\end{array}$ & \\
\hline $\begin{array}{l}\text { - Strong restraints in daily and recreational } \\
\text { activities;walker, crutches, wheelchair, orthosis } \\
\text { (ankle restraint,ankle immobilizer) }\end{array}$ & 0 \\
\hline Maximum walking distance, in blocks & \\
\hline - Less than 1 & 0 \\
\hline Walking surfaces & \\
\hline $\begin{array}{l}\text { - Strong difficulties on irregular floors, stairs, } \\
\text { steeps and hills }\end{array}$ & 0 \\
\hline Gait abnormality & \\
\hline - No abnormality, mild & 8 \\
\hline Sagittal mobility (flexion + extension) & \\
\hline - Moderate limitation (15o-29o) & 4 \\
\hline Hindfoot mobility (inversion + eversion) & \\
\hline $\begin{array}{l}\text { - Normal or slightly limited }(75-100 \% \text { of the } \\
\text { normal mobility) }\end{array}$ & 6 \\
\hline $\begin{array}{l}\text { Ankle-Hindfoot stability (anteroposterior, } \\
\text { varus-valgus) }\end{array}$ & \\
\hline - Stable & 8 \\
\hline Alignment (10 points) & \\
\hline $\begin{array}{l}\text { - Good, plantigrade foot, well-aligned forefoot and } \\
\text { hindfoot }\end{array}$ & 10 \\
\hline TOTAL SCORE:_76_ & \\
\hline
\end{tabular}
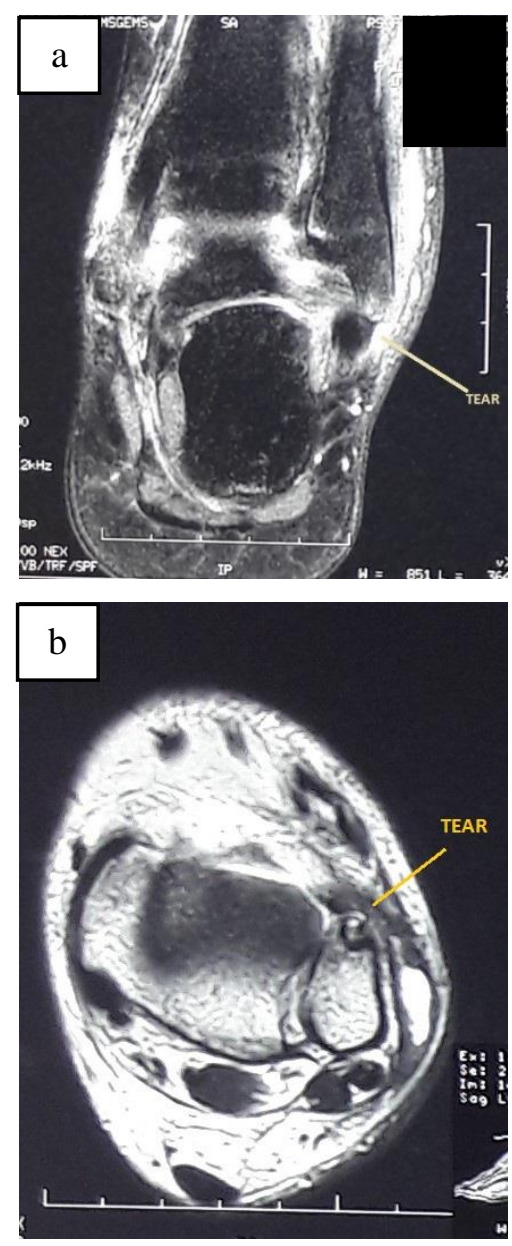

Gambar 7. MRI ankle sinistra. (a) coronal, (b) axial

\section{Penatalaksanaan}

Dilakukan rekonstruksi anterior talofibular ligamen dengan menggunakan teknik modified Brostrom-Gould.

\section{Follow up}

Evaluasi setelah 3 bulan pasien sudah bisa melakukan aktivitas sehari-hari. Pada gambar 8 tampak posisi berdiri yang kokoh setelah 3 bulan. Pada pemeriksaan anterior drawer test negatif (Gambar 11), varus stress test negatif (Gambar 10), valgus 


\section{Laporan Kasus}

Vol 8 No. 2, Oktober 2019

ISSN 2460-8742

http://journal.unair.ac.id/ORTHO@journal-orthopaedi-and-traumatology-surabaya-media-104.html

stress test negatif (Gambar 9), serta skor

AOFAS excellent (100) (Tabel 5).

Tabel 5. Skor AOFAS pasca rekonstruksi AOFAS ANKLE-HINDFOOT SCALE

\begin{tabular}{|c|c|}
\hline \multicolumn{2}{|l|}{ AOFAS ANKLE-HINDFOOT SCALE } \\
\hline Pain & \\
\hline - No pain & 40 \\
\hline $\begin{array}{l}\text { Functional ( } 50 \text { points) Restraints in } \\
\text { activities, support required }\end{array}$ & \\
\hline - No restraints, no support & 10 \\
\hline Maximum walking distance, in blocks & \\
\hline - More than 6 & 5 \\
\hline Walking surfaces & \\
\hline $\begin{array}{l}\text { - Some difficulty on irregular floors, stairs, } \\
\text { steeps and hills }\end{array}$ & 3 \\
\hline Gait abnormality & \\
\hline - No abnormality, mild & 8 \\
\hline Sagittal mobility (flexion + extension) & \\
\hline - Normal or slightly limited (30॰ or more) & 8 \\
\hline Hindfoot mobility (inversion + eversion) & \\
\hline $\begin{array}{l}\text { - Normal or slightly limited (75- } 100 \% \text { of the } \\
\text { normal mobility) }\end{array}$ & 6 \\
\hline $\begin{array}{l}\text { Ankle-Hindfoot stability (anteroposterior, } \\
\text { varus-valgus) }\end{array}$ & \\
\hline - Stable & 8 \\
\hline Alignment (10 points) & \\
\hline $\begin{array}{l}\text { - Good, plantigrade foot, well-aligned forefoot } \\
\text { and hindfoot }\end{array}$ & 10 \\
\hline TOTAL SCORE:_100 & \\
\hline
\end{tabular}
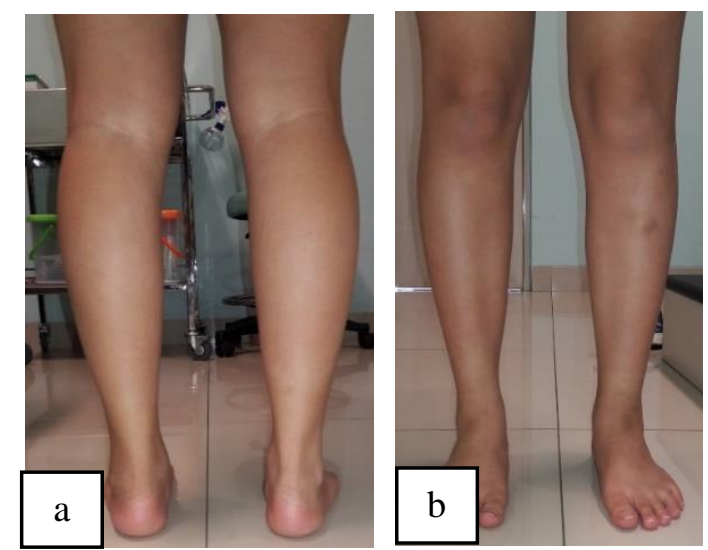

Gambar 8. Tiga bulan setelah reksonstruksi ATFL

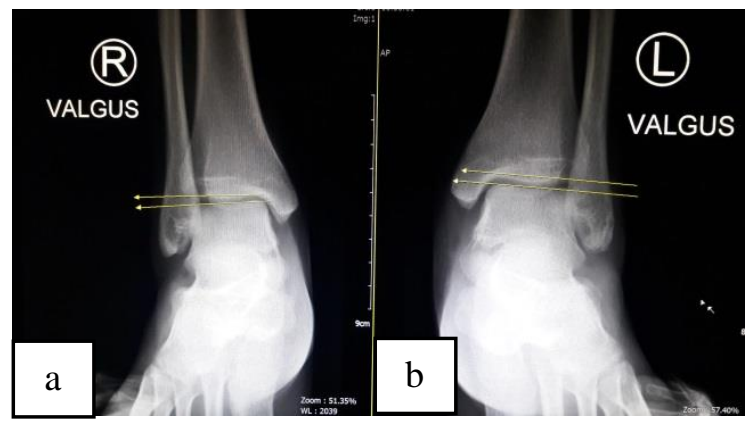

Gambar 9. Valgus stress test. (a) kanan,

(b) kiri

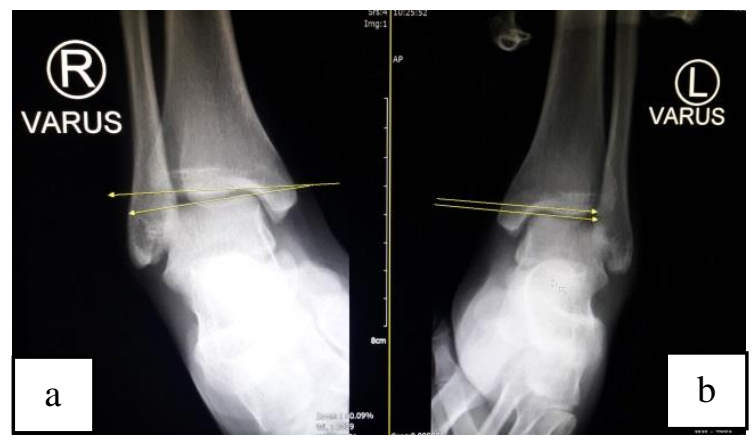

Gambar 10. Varus stress test. (a) kanan,

(b) kiri

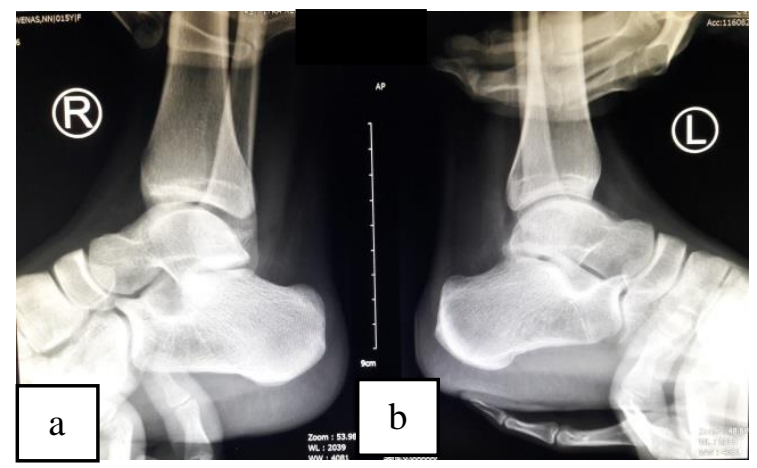

Gambar 11. Anterior drawer test. (a) kanan, (b) kiri

\section{DISKUSI}

Pada kedua kasus yang telah dilaporkan diatas, yakni wanita 15 tahun dan pria 21 tahun datang dengan keluhan nyeri pada ankle, nyeri bertambah jika 


\section{Laporan Kasus}

digerakan, sendi kaki dirasakan goyang jika berjalan. Mekanisme trauma pada kedua kasus ini adalah terjatuh dengan posisi punggung kaki tertekuk (plantar fleksi) ketika olahraga, dan ini sesuai patofisiologi penyebab cedera yang paling sering terjadi pada cedera ATFL.

Pemeriksaan fisik yang rutin dilakukan untuk identifikasi kerusakan ATFL adalah anterior drawer test, dengan cara mendorong calcaneus ke anterior atau dengan cara menekan tibia ke posterior. Pada kedua pasien ditemukan anterior drawer test positif. Selain itu juga dilakukan penilaian berdasarkan AOFAS ankle-hindfoot scale, dengan melakukan penilaian beberapa aspek yaitu pain, functional restraints in activities, maximum walking, walking surface gait abnormality, sagital mobility, hind foot mobility, anklehind foot stability dan alignment. Total maksimal 100 poin. Pada kedua pasien diatas didapatkan nilai kategori Fair (cukup), 76 poin (Tabel 3) pada wanita 15 tahun dan 53 poin (Tabel 1) pada pria 21 tahun. Pada pasien ini tidak dilakukan pemeriksaan X-ray varus valgus stress test karena ankle pasien masih mengalami eritem dan swelling sehingga untuk memastikan diagnosa pada kedua pasien ini dilakukan pemeriksaan MRI. Dari pemeriksaan MRI didapatkan adanya tear dari ligamen anterior talofibular.
Setelah

dilakukan

semua pemeriksaan dilakukan tatalaksana operatif pada kedua pasien yakni rekonstruksi ATFL dengan teknik Brostrom-Gould modifikasi yaitu suatu teknik rekonstruksi ATFL dengan cara menjahit remnant ATFL ke tip dari fibula dan inferior retinaculum ke priosteum dari tip fibula. Setelah dilakukan tatalaksana operatif, kedua pasien di follow up 3 bulan setelah operasi pada pasien ke-2 dan 2 bulan pascaoperasi pada pasien pertama dengan menggunakan AOFAS Ankle-hindfoot scale. Pada kedua pasien didapatkan hasil yang sangat maksimal, terjadi peningakatan score AOFAS (Tabel 2 dan 5) ke nilai maksimal 100 poin (excellent). Selain itu juga dilakukan penilaian stabilitas ankle yang kokoh yang dibuktikan dengan foto X-ray menggunakan beban, yakni tidak terdapat pergeseran pada foto anterior drawer test dan tidak terdapat kelainan pada varus valgus stress test pada pasien kedua. Namun anterior drawer test pada pasien pertama masih memperlihatkan hasil postif hal ini disebabkan oleh beberapa faktor yakni pemeriksaan dilakukan pada bulan kedua, masih berada pada regenerasi dan perbaikan (fase fibroelastik/fase pembentukan kolagen) yang masih memungkinkan laxity. Sedangkan fase remodeling dimulai pada bulan ke-3 sampai bulan ke-12, serta pasien ini mengalami deltoid ligament tear. Pada saat sekarang 
ini pasien sudah bisa beraktivitas seperti biasa tanpa mengeluhakan nyeri dan gangguan dalam berjalan.

Hasil tersebut sesuai dengan penelitian sebelumnya dengan subjek penelitian chronic lateral ankle instability yang menunjukkan bahwa dari 41 pasien; 27 pasien sangat puas, 11 puas dan 3 tidak puas. Mobilitas pergelangan kaki kembali normal pada $93 \%$ pasien. Pada tindak lanjut AOFAS adalah 89/100 (37-100), FAAM 85/100\% (35-100\%), CAIT 20/30 (5-30), dan CAIS 74/100\% (27- 100\%). Hasil lainnya juga ditemukan pada penelitian Wainright et al. yang menyatakan bahwa perbaikan modifikasi Brostrom gould meningkatkan pergerakan abnormal persendian yang diamati pada pasien dengan lateral instability, mengurangi translasi anterior dan rotasi internal talus.

\section{KESIMPULAN DAN SARAN}

Berdasarkan pemaparan di atas, dapat disimpulkan bahwa teknik modifikasi Brostrom-gould dapat digunakan sebagai teknik untuk rekonstruksi anterior talofibular ligament (ATFL). Setelah dilakukan follow up, tidak terdapat pergeseran pada foto anterior drawer test dan tidak terdapat kelainan pada varus valgus stress test pada pasien kedua. Namun anterior drawer test pada pasien pertama masih memperlihatkan hasil positif. Hal ini disebabkan oleh beberapa faktor yakni pemeriksaan dilakukan pada bulan kedua, masih berada pada regenerasi dan perbaikan yang masih memungkinkan laxity. Saat sekarang ini pasien sudah bisa beraktivitas seperti biasa tanpa mengeluhakan nyeri dan gangguan dalam berjalan.

\section{REFERENSI}

1. Behrens, Steve B, Mark Drakos, Byung J Lee, Dave Paller, Eve Hoffman, Sarath Koruprolu, and Christopher W Digiovanni. Biomechanical Analysis of Brostrom Versus Brostrom-Gould Lateral Ankle Instability Repairs. Foot \& Ankle International 2015;34(4): 587-592.

2. Buerer, Yannick, Michaela Winkler, Alexandre Burn, Swati Chopra Pt, and Xavier Crevoisier. Foot and Ankle Surgery - Gould Procedure for Treatment of Chronic Evaluation of a Modified Brostro Lateral Ankle Instability : A Retrospective Study with Critical Analysis of Outcome Scoring. Foot and Ankle Surgery 2013;19(1): 36-41.

3. Trč, Tomáš, Milan Handl, and Vojtech Havlas. The Anterior Talo-Fibular Ligament Reconstruction in Surgical Treatment of Chronic Lateral Ankle Instability. International Orthopaedics 2010;34: 991-96.

4. Wainright, William B, Charles E Spritzer, Jun Young Lee, Mark E Easley, James K Deorio, James A Nunley, and Louis E Defrate. The Effect of Modified Brostrom-Gould Repair for Lateral Ankle Instability on In Vivo Tibiotalar Kinematics. Am J Sports Med 2009;40(9): 2099-2104.

5. Croy T, Koppenhaver S, Saliba S, Hertel J. Anterior talocrural joint laxity: diagnostic accuracy of the anterior drawer test of the ankle. $J$ Orthop Sport Phys Ther 2013; 
43(12):911-919.

6. Oae K, Takao M, Uchio Y, Ochi M. Evaluation of anterior talofibular ligament injury with stress radiography, ultrasonography and MR imaging. Skeletal Radiol 2010; 39(1):41-47.

7. W Wolfe M, Uhl T, Mattacola C, C McCluskey L. Management of Ankle Sprains; 63: 2001.

8. Kaminski TW, Hertel J, Amendola N, Docherty CL, Dolan MG, Hopkins Jty et al. National Athletic Trainers' Association Position Statement: Conservative Management and Prevention of Ankle Sprains in Athletes. J Athl Train. 2013;48(4):528545.

9. Eugene C. Modified Brostrom-Gould Technique for Lateral Ankle Ligament Reconstruction. Company Publication. https://www.arthrex.com/link/asset/sjje 6fkEEeCRTQBQVoRHOw. Published 2018.

10. Pena F, Agel J, Coetzee JC. Comparison of the MFA to the AOFAS Outcome Tool in a Population Undergoing Total Ankle Replacement. Foot Ankle Int. 2007;28(7):788-793.

11. Lee KT, Park YU, Kim JS, Kim JB, Kim KC, Kang SK. Long-Term Results after Modified Brostrom Procedure without Calcaneo-fibular Ligament Reconstruction. Foot Ankle Int. 2011;32(2):153-7. 